\title{
Innovations
}

\section{Preparing medical students for the writing of history of present illness: Marching from short story reading and the practice of visual art}

\author{
Medical Humanities in the Middle East Conference
}

\author{
November 17-18, 2018 \\ Doha, Qatar
}

\section{Authors}

Pi-Hua Tsai ${ }^{\star}$

\section{Abstract}

The study of literature is believed to be beneficial to the development of the necessary competencies required of medical students/ doctors, such as skills of observation and interpretation, as well as empathy for patients. According to Bramstedt, ${ }^{1}$ it is essential that medical students develop observation skill, which is rarely explicitly taught, before learning to make diagnosis and treatment because it may be related to how they listen to patients, and how they make reflective and analytical thinking about their illness. Nevertheless, very few interdisciplinary course designs have been found that integrated the study of literature with medical humanities education.
This study aims to explore how the study of literature and practice of visual art can be incorporated into an English language course to prepare for the students' medical writing of history of present illness (HPI), which describes chronologically the progression of the patient's present illness from the first sign and symptom to the present. The writing of HPI includes chief complaint, narrative account of the illness, detailed description of symptoms (e.g. location, severity and duration), past history and family history of the present illness, and patient's social life.

A suitable reading choice of literary works can result in a good guidance to the writing of history of present illness. Choosing a literary text that has characters whose personal traits and background might be seen in clinic encounters may be helpful for medical students to imagine what their clientsto-be will be like in the future and what problems
Mackay Medical College, Taipei, Taiwan

*Email: tsaipihua@gmail.com

\begin{abstract}
Cite this article as:
Tsai PH. Preparing medical students for the writing of history of present illness: Marching from short story reading and the practice of visual art. In: Weber AS, Verjee MA, editors. Proceedings of the 1st International Conference on Medical Humanities in the Middle East [Internet]; 2018 Nov 17-18: Doha, Qatar: Innovations in Global Health Professions Education; 2019 March. p. 56-57. (Innovations in Global Health Professions Education; vol. 2019, spec. no.: 1). https://dx.doi.org/10.20421/ ighpe2019.01.20

This is an open access article distributed under the terms of the Creative Commons Attribution license CC BY 4.0, which permits unrestricted use, distribution and reproduction in any medium, provided the original work is properly cited.
\end{abstract}


they may come up with, such as psychological ones. The dramatic life of a character in a story may impress students so much that it is very likely for them to come up with some HPI that depicts his/her conditions well.

This study adopted Howard Gardner's Theory of Multiple Intelligences to integrate the study of literature (e.g. short stories) to an English language course so that the course is motivating to medical students and they can be aware of social issues that are related to the character's life. Howard Gardner's Theory of Multiple Intelligences underscores that human beings' strengths are multifaceted. Eight intelligences are posited to account for human potential: linguistic, logicalmathematical, musical, spatial, bodily-kinesthetic, interpersonal and intrapersonal intelligences. ${ }^{2}$

Forty-three medical students read the short story "A Rose for Emily" by William Faulkner. The students first learned a number of English vocabulary words by category (e.g., 'aging' and 'light'). They then were told to draw and write descriptions of their favorite scenes. After that, they drew and depicted the characters' appearance features, emotions and even their clothing. Their creative works were collected and published as anecdotes that document their exploration of humanity (an e-book of students' works is available at http://www.holistic.mmc.edu. tw/ARoseforEmilyimage/FreeVersion/Default.html). Finally, in conjunction with learning how to do an HPI, they were told to write up an HPI for the fictional character Emily by imagining she was their patient.

The students' illustrations and written descriptions revealed their awareness of the social value of Emily's life, their profound depiction of her appearance, and their understanding of her psychological world. Six themes that were associated with HPI writing were identified: social change, women's role, description of light and characters, empathy for the characters and imagination.

The purpose of this course design is three-fold. First, it is hoped that a close reading of a short story and students' practice of creativity through arts can expand their imagination about what patients' illness may be like and be conducive to enhancing their empathy for future patients. Second, it showed that multiple intelligences can be used for sharpening medical students' creativity and observation skills. Their creative works can also be published as anecdotes that document their exploration of humanities. Such a design can help medical students learn not only literature but also the issues of medical humanities, which is crucial to their communication with patients in the future and can prepare for their writing of HPI.

Conflicts of interest: None.

Funding sources: None.

\section{References}

1. Bramstedt KA. The use of visual arts as a window to diagnosing medical pathologies. AMA J Ethics [Internet]. 2016 [cited 2018 Nov 28]; 18(8):843-54. Available from: https://doi.org/10.1001/ journalofethics.2016.18.8.imhl1-1608 doi:10.1001/journalofethics.2016.18.8.imhl1-1608

2. Gardner H. Multiple intelligences: the theory in practice. New York, NY: Basic Books; 1993. $304 \mathrm{p}$.

\section{About the author}

Dr. Tsai Pi-Hua, Ph.D., with her Ph.D. in the TESOL, has been teaching English for over three decades, and is currently the Director of the Center of Holistic Education of Mackay Medical College, Taipei, Taiwan. Her abundant teaching experience has kindled her research interests in discourse analysis, computerassisted pronunciation teaching and learning, and medical humanities. 